\title{
Author Index to Volume 5
}

Angell, I. O., 168

Bacon, C. J., 84

Bray, I., 37

Britton, C., 27

Collier, P. A., 134

Edeleanu, C., 94

Fitzgerald, G., 5

Gough, T., 161

Harris, M., 49

Hochstrasser, B., 215

Hosking, D., 141

Hunt, G. E., 105
Jackson, I. F., 141

James, E., 94

Jamieson, R., 63

Jones, O., 37

Kaye, G. R., 73

Leeming, A., 175, 236

Lister, P., 94

Loomes, M., 33

Low, G., 63

Moreton, R., 100

MSA Business Survey, 41

Omer, K., 27

Palmer, C., 232
Peters, G., 205

Roberts, A., 161

Silk, D., 185

Smith, N. C., 123

Spaul, B. J., 134

Symons, V., 194

Tate, G, 12

Taylor, J., 151

Verner, J. M., 12, 51

Ward, J., 222

Webster, S., 37

Willcocks, L., 110

Williams, H., 151 